\title{
Properties of Metal-Doped Covalent Organic Frameworks and Their Interactions with Sulfur Dioxide
}

\author{
Ju Wang $\mathbb{D},{ }^{1}$ Jia Wang, ${ }^{2}$ Wenchang Zhuang, ${ }^{1}$ Xiaoqin Shi, ${ }^{1}$ and Xihua Du ${ }^{1}$ \\ ${ }^{1}$ School of Chemistry and Chemical Engineering, Xuzhou University of Technology, Xuzhou 221018, China \\ ${ }^{2}$ School of Public Health, Taishan Medical University, Taian 271016, China \\ Correspondence should be addressed to Ju Wang; wangju@xzit.edu.cn
}

Received 4 January 2018; Revised 16 April 2018; Accepted 24 May 2018; Published 11 July 2018

Academic Editor: Franck Rabilloud

Copyright $\odot 2018$ Ju Wang et al. This is an open access article distributed under the Creative Commons Attribution License, which permits unrestricted use, distribution, and reproduction in any medium, provided the original work is properly cited.

Covalent organic frameworks are unique for their highly open architecture and attractive for use as promising gas adsorption and storage carriers. In this work, density functional theory calculations have been performed to investigate the properties of metaldoped covalent organic frameworks and their interactions with the $\mathrm{SO}_{2}$ gas molecule. It is found that a single metal atom (including Li, $\mathrm{Na}, \mathrm{K}$, and $\mathrm{Sc}$ ) doped at the top of phenyls within the tetra(4-dihydroxyborylphenyl) silane (TBPS) building block of covalent organic frameworks can easily lose its valence electrons and can be positively charged. The $\mathrm{SO}_{2}$ gas molecule could be stably absorbed onto the metal-doped covalent organic frameworks. The absorbed $\mathrm{SO}_{2}$ molecule interacts with $\mathrm{Li}, \mathrm{Na}, \mathrm{K}$, and $\mathrm{Sc}$ metal-doped covalent organic frameworks by the dominant donor-acceptor delocalization between 1-center lone pair of an oxygen atom within $\mathrm{SO}_{2}$ and 1-center non-Lewis lone pairs of the doped metal atom.

\section{Introduction}

Sulfur dioxide gases, mainly resourced from industrial activities, are known as the major source of atmospheric pollution leading in particular to acid smog formation and acid rain $[1,2]$. Reducing sulfur dioxide emission has become one of the most important social and environmental challenges [3-5]. It should be pointed out that adsorption by porous nanomaterials is recognized as an efficient and economical approach for capture of low concentration $\mathrm{SO}_{2}$ from mixture gases [6-10]. Covalent organic frameworks (COFs) are ideal porous materials for gas capture due to their low density, good stability, and large surface area [11-15]. Target covalent organic framework porous materials have been designed and synthesized for sulfur dioxide gases adsorption and separation. Lee et al. developed functionalized covalent organic frameworks reversible for $\mathrm{SO}_{2}$ and highly stable on repeated adsorption-desorption cycles [16].

Doping of metals into covalent organic frameworks is one of the most effective modifications of covalent organic frameworks for gases capture [17-20]. Experimental and theoretical studies have been carried out to explore on the doping of metals into covalent organic frameworks in order to enhance their capture for hydrogen and carbon dioxide gases. Yang et al. doped metal Pd clusters onto COF-1 materials and enhanced their hydrogen storage properties under mild conditions [21]. Guo et al. reported the doping of Pt cluster onto covalent organic frameworks and investigated hydrogen spillover reaction mechanism [22]. Stegbauer et al. reported $\mathrm{CO}_{2}$ sorption properties in two isostructural azine-linked covalent organic frameworks based on 1,3,5-triformyl benzene (AB-COF) and 1,3,5-triformylphloroglucinol (ATFGCOF) and hydrazine building units, respectively [23]. However, there are few studies focused on $\mathrm{SO}_{2}$ gases adsorption and separation on the metal-doped covalent organic frameworks and the interactions between the metal-doped covalent organic frameworks and $\mathrm{SO}_{2}$ gases.

In this work, density functional theory calculations have been performed to investigate the properties of metal-doped covalent organic frameworks and their interactions with $\mathrm{SO}_{2}$ gas. Considering the excellent doping effect of alkali metals and transition metals into the covalent organic framework for hydrogen and carbon dioxide [17-23], we thus choose alkali ( $\mathrm{Li}, \mathrm{Na}$, and $\mathrm{K}$ ) and transition metals (Sc) doped into 


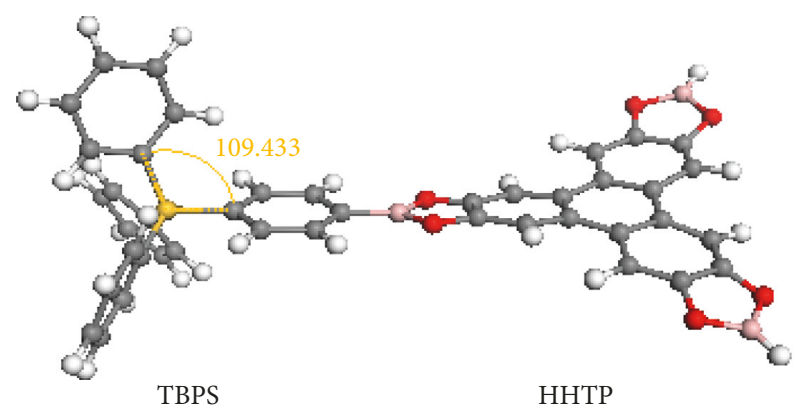

FIgURE 1: The cluster model of covalent organic frameworks (COF105). Dark yellow: Si; dark grey: C; grey: H; pink: B; red: O.

TABLE 1: The energy of optimized metal@COF-105 and interaction energy between the doped metal and the COF-105 cluster model.

\begin{tabular}{lcccc}
\hline Metal@ & \multicolumn{2}{c}{$\alpha^{1}$} & \multicolumn{2}{c}{$\beta^{2}$} \\
COF-105 & $E$ (a.u.) & $\Delta E(\mathrm{kcal} / \mathrm{mol})$ & $E$ (a.u.) & $\begin{array}{c}\Delta E \\
(\mathrm{kcal} / \mathrm{mol})\end{array}$ \\
\hline Li@COF-105 & -2439.86 & -60.13 & -2407.26 & -8.05 \\
Na@COF-105 & -2594.63 & -42.51 & -2516.35 & -7.86 \\
K@COF-105 & -3032.26 & -31.15 & -3002.14 & -6.59 \\
Sc@COF-105 & -3192.99 & -141.38 & -3176.89 & -11.26 \\
\hline
\end{tabular}

$\alpha^{1}$ : at the top of the phenyl within TBPS; $\beta^{2}$ : at the top of the phenyl within HHTP.

covalent organic frameworks and investigated properties of the metal-doped covalent organic frameworks and their interactions with the $\mathrm{SO}_{2}$ gas molecule. The main focus is to understand the metal doping into covalent organic frameworks and their influence on sulfur dioxide capture.

\section{Computational Details}

The cluster model of covalent organic frameworks presented in Figure 1 consisting of the tetra(4-dihydroxyborylphenyl) silane (TBPS) and 2,3,6,7,10,11-hexahydroxy triphenylene (HHTP) building blocks selected from COF-105 [24] is adopted to represent the real structure of COF-105 for the saving computational cost. The cutoff functional groups of the covalent organic framework cluster model are saturated by hydrogen. Considering the different doping sites, alkali $(\mathrm{Li}, \mathrm{Na}$, and $\mathrm{K}$ ) and transition $(\mathrm{Sc})$ metals were doped into the cluster model of COF-105, respectively. All geometry optimization and frequency analysis calculations were done by the hybrid density functional B3LYP [25] and 6-31G(d) basis set. Interaction energy calculations were performed at B3LYP/6-311 + G(d,p)//B3LYP/6-31G(d) level of theory with counterpoise algorithm to eliminate the overlap error of basis functions [26]. AIM and NBO calculations based on the optimized geometries at B3LYP/6-31G(d) level of theory were further carried out to analyze, evaluate, and classify the nature of the interactions within the metal-doped COF-105 complexes and their interactions with the absorbed sulfur dioxide gas molecule. Gaussian 09 package [27], AIM 2000 software [28], and NBO 5.9 program implemented in the Gaussian 09 package have been used for all geometry optimization, frequency analysis, AIM, and NBO calculations.

\section{Results and Discussion}

3.1. Properties of the Metal-Doped COF-105 Complexes. In this section, we firstly focus on the possible doping sites of the metal and the stability of the metal-doped covalent organic framework complexes. Table 1 lists the energies of the stable metal-doped covalent organic framework complexes and the metal-COF interaction energies obtained by subtracting the energies of the metal atom and covalent organic frameworks from the energy of the $\mathrm{Li}, \mathrm{Na}, \mathrm{K}$, and $\mathrm{Sc}$ metal-doped COF-105 complex, respectively. Much higher interaction energies when doping at TBPS sites than those at HHTP sites indicate that the phenyl of the TBPS building blocks in COF-105 offers the most favorable doping sites for $\mathrm{Li}, \mathrm{Na}, \mathrm{K}$, and Sc metals. The main reason is that the tetrahedral structure of the TBPS building block provides more $\mathrm{C}$ and $\mathrm{B}$ atoms interacting with the doped metal atoms than those in the HHTP building block within COF-105.

Figure 2 and Table 2 show the optimized geometries of the metal-doped complexes when $\mathrm{Li}, \mathrm{Na}, \mathrm{K}$, and $\mathrm{Sc}$ metals are doped at the top of the phenyl of the TBPS building block of the covalent organic framework cluster model, regarded as Li@COF-105, Na@COF-105, K@COF-105, and Sc@COF-105, respectively. When alkali metals Li, Na, and $\mathrm{K}$ are doped at the top of the phenyl within the TBPS building blocks of COF-105 cluster, the interaction energy between the doped metal and covalent organic frameworks is $-60.13 \mathrm{kcal} / \mathrm{mol},-42.51 \mathrm{kcal} / \mathrm{mol}$, and $-31.15 \mathrm{kcal} / \mathrm{mol}$, respectively. As shown in Figure 2, the bond angle $\mathrm{C} 1-\mathrm{Si}$ $\mathrm{C7}$ in the alkali metal $\mathrm{Li}, \mathrm{Na}, \mathrm{K}$ doped covalent organic framework complexes is $94.16^{\circ}, 97.65^{\circ}$, and $100.64^{\circ}$, respectively. The distance (presented in Table 2) between $\mathrm{C} 1$ and the doped metal atom in the complexes Li@COF-105, Na@COF-105, and K@COF-105 is $2.454 \AA$, $2.728 \AA$, and $3.163 \AA$, respectively. The distance between $\mathrm{C} 7$ and the doped-metal atoms (Li, Na, K) in the complexes Li@COF-105, Na@COF-105, and K@COF-105 is $2.346 \AA, 2.719 \AA$, and $3.214 \AA$, respectively. These results indicate that the smaller the angle $\mathrm{C} 1-\mathrm{Si}-\mathrm{C} 7$ in the metal-doped complexes Li@COF-105, Na@COF-105, and K@COF-105, the greater is the interaction energy between the doped-metal and covalent organic frameworks.

The bond angle C1-Si-C7 is $91.10^{\circ}$ in Sc@COF-105, with the distances of C1-Sc and C7-Sc being $2.359 \AA$ and $2.457 \AA$, respectively, smaller than those in alkali metal-doped covalent organic framework complexes. In addition, the interaction energy of the transition Sc metal with the COF-105 cluster $(-141.38 \mathrm{kcal} / \mathrm{mol})$ is significantly higher than those of alkali metal-doped COF-105 complexes. Figure 3 shows the electrostatic potential distributions of the metal-doped COF-105 complexes with the surface electronic density criterion being $0.001 \mathrm{e} / \mathrm{bohr}^{3}$. The maximum electrostatic potential of the metal-doped complexes Li@COF-105, Na@ COF-105, and K@COF-105 is 225.63 a.u., 188.75 a.u., and 151.99 a.u., respectively. Different from the alkali metaldoped COF-105 complexes, there are two maximum electrostatic potential points in Sc@COF-105, with electrostatic potential being 162.98 a.u. and 164.85 a.u., respectively. The electrostatic potential distribution results reveal that a single metal atom (including alkali metal $\mathrm{Li}, \mathrm{Na}, \mathrm{K}$, and transition 


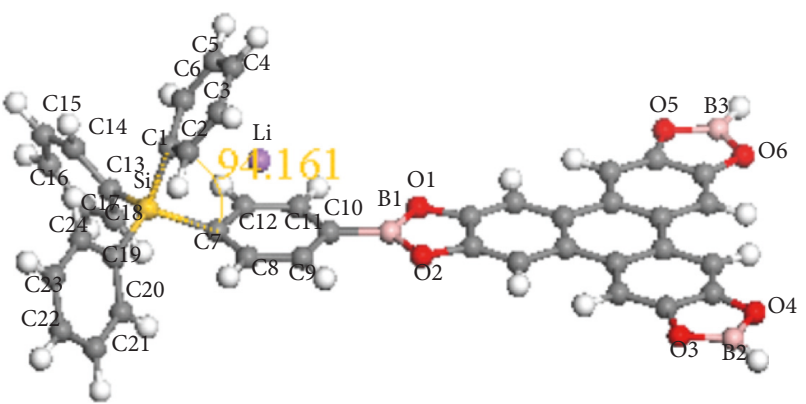

(a)

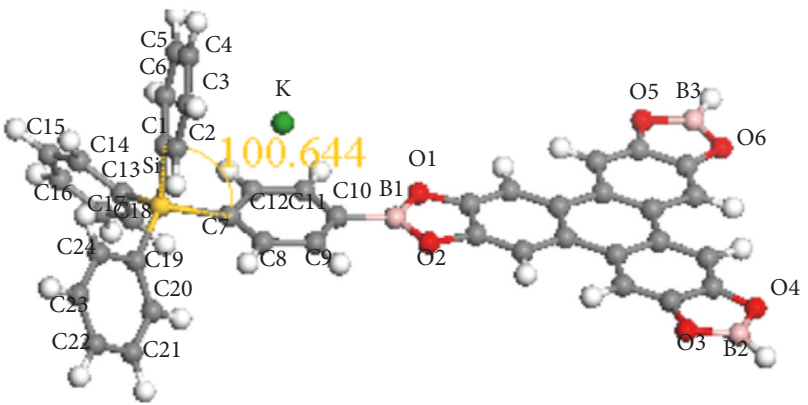

(c)

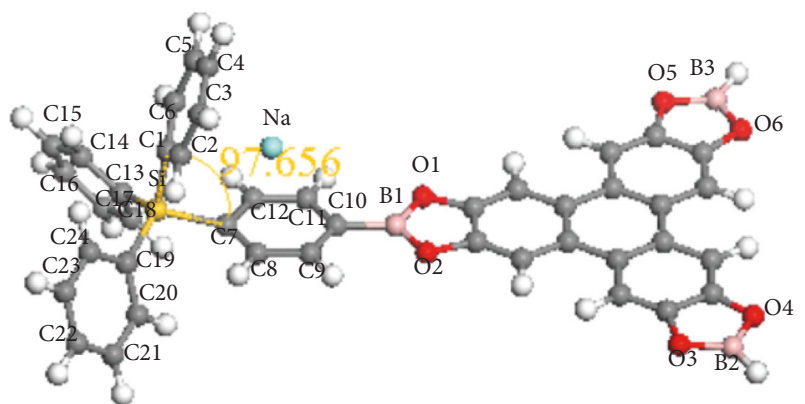

(b)

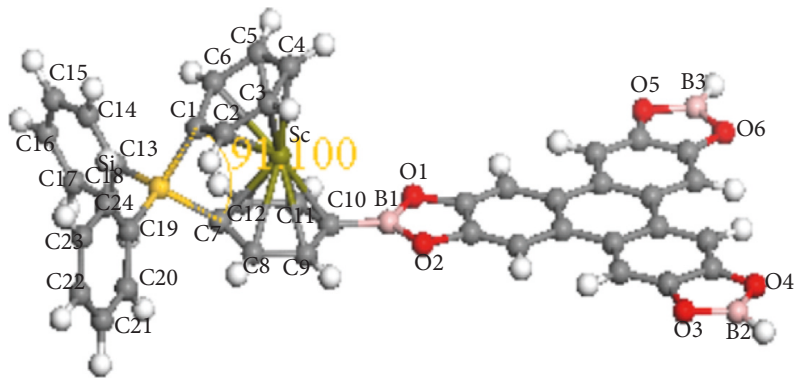

(d)

Figure 2: Optimized geometries of all the metal-doped COF-105 complexes. Dark yellow: Si; dark grey: C; grey: H; pink: B; red: O; purple: Li; blue: Na; green: K; breen: Sc. Partial atom numbers of C, B, and O atoms were presented. (a) Li@COF-105. (b) Na@COF-105. (c) K@ COF-105. (d) Sc@COF-105.

TABle 2: Partial geometrical data of the metal-doped complexes (metal@COF-105).

\begin{tabular}{|c|c|c|c|c|}
\hline Angle $\left(^{\circ}\right)$ /atom distances $(\AA)$ & Li@COF-105 & Na@COF-105 & K@COF-105 & Sc@COF-105 \\
\hline $\mathrm{C} 1-\mathrm{Si}-\mathrm{C} 7$ & 94.16 & 97.65 & 100.64 & 91.10 \\
\hline C1-metal & 2.454 & 2.728 & 3.163 & 2.359 \\
\hline C2-metal & 2.330 & 2.840 & 3.225 & 2.478 \\
\hline C3-metal & 2.688 & 3.038 & 3.362 & 2.538 \\
\hline C4-metal & 2.465 & 3.115 & 3.425 & 2.471 \\
\hline C5-metal & 2.699 & 3.016 & 3.363 & 2.538 \\
\hline C6-metal & 2.810 & 2.818 & 3.224 & 2.477 \\
\hline C7-metal & 2.346 & 2.719 & 3.214 & 2.331 \\
\hline C8-metal & 2.494 & 2.821 & 3.342 & 2.457 \\
\hline C9-metal & 2.779 & 2.986 & 3.413 & 2.484 \\
\hline C10-metal & 2.907 & 3.055 & 3.342 & 2.400 \\
\hline C11-metal & 2.787 & 2.956 & 3.214 & 2.484 \\
\hline C12-metal & 2.504 & 2.793 & 3.157 & 2.457 \\
\hline B1-metal & 4.001 & 4.148 & 4.422 & 3.502 \\
\hline
\end{tabular}

metal Sc) doped at the top of phenyls within the TBPS building block can easily lose its valence elections and can be positively charged. And, the metal-doped COF-105 complexes Li@COF-105,Na@COF-105,K@COF-105, and Sc@ COF-105 could exist stably.

\subsection{Interactions between Metal@COF-105 and Sulfur Dioxide.} In this section, we focus on the interactions between the metal-doped COF-105 complex and the absorbed sulfur dioxide gas molecule in order to investigate the effect of metal-doping into COF-105 for sulfur dioxide capture. Here, the adsorption complexes were regarded as $\mathrm{SO}_{2} / \mathrm{Li} @ \mathrm{COF}-$ 105, SO $2 / \mathrm{Na@COF-105,SO} 2 / \mathrm{K} @ C O F-105$, and SO $2 / \mathrm{Sc} @$
COF-105, respectively, where sulfur dioxide gas molecule was absorbed onto the $\mathrm{Li}, \mathrm{Na}, \mathrm{K}$, and $\mathrm{Sc}$ metal-doped COF105 complexes.

Figure 4 and Table 3 display all the optimized geometries of the adsorption complexes $\mathrm{SO}_{2} /$ metal@COF-105, in which the metals ( $\mathrm{Li}, \mathrm{Na}, \mathrm{K}$, and $\mathrm{Sc}$ ) are doped at the top of the phenyl of the TBPS building blocks in the COF-105 cluster model. AIM calculations were further performed to investigate the weak interactions within the adsorption complexes $\mathrm{SO}_{2} /$ metal@COF-105, as shown in Table 4 .

When a Li atom, doped at the top of the phenyls in the TBPS building block of COFs, is positively charged, it can absorb one $\mathrm{SO}_{2}$ molecule with the interaction energy of $-25.46 \mathrm{kcal} / \mathrm{mol}$ obtained by subtracting the energies of 


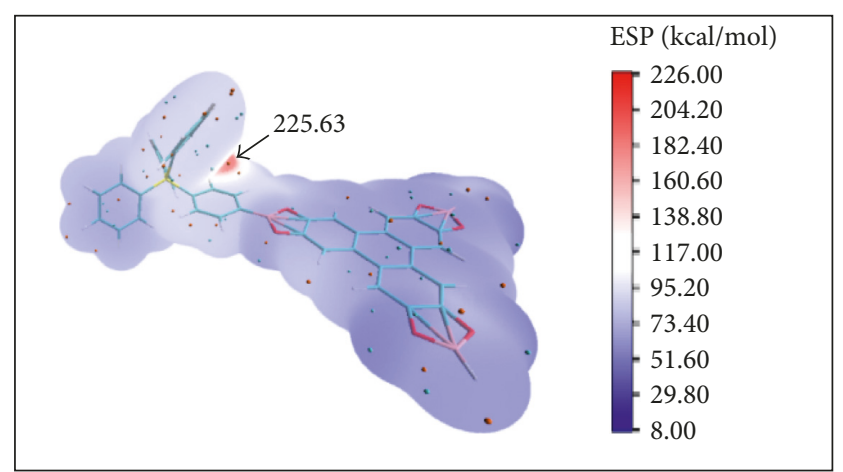

(a)

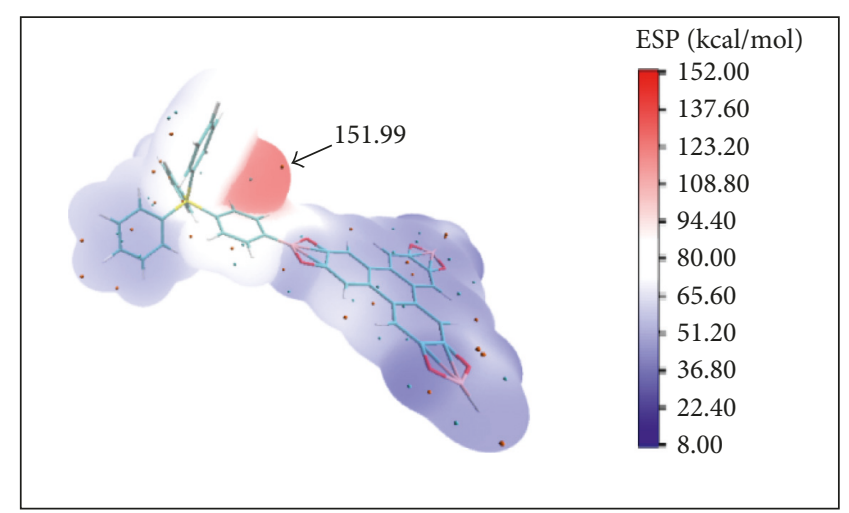

(c)

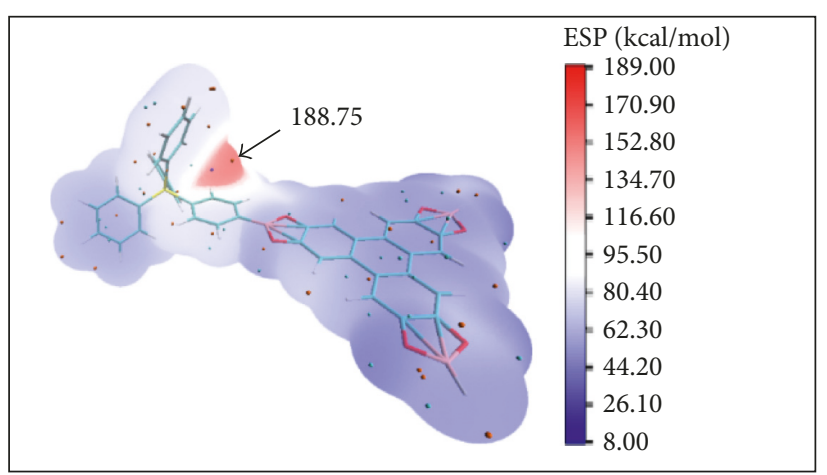

(b)

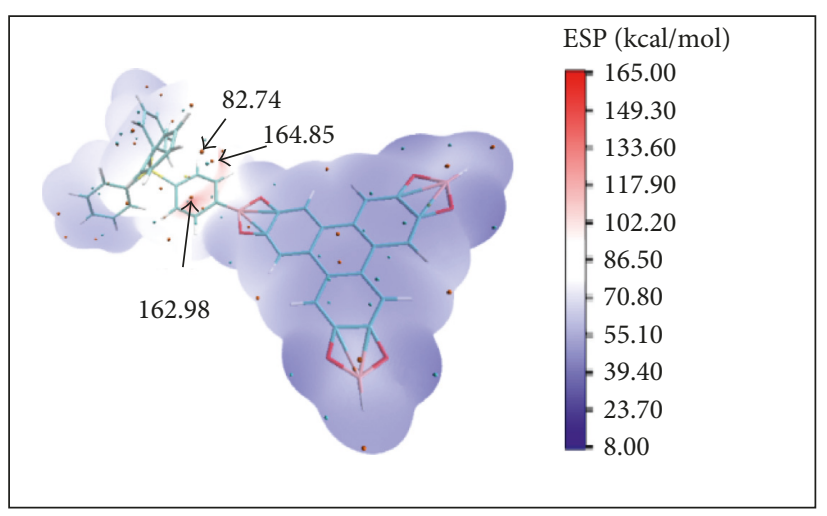

(d)

Figure 3: Electrostatic potential distribution of all the metal-doped complexes (metal@COF-105). (a) Li@COF-105. (b) Na@COF-105. (c) K@COF-105. (d) Sc@COF-105.

sulfur dioxide and the metal-doped covalent organic frameworks from the energy of the adsorption complexes $\mathrm{SO}_{2} / \mathrm{Li} @$ COF-105. As shown in Figure 4, the $\mathrm{SO}_{2}$ gas molecule nearly lies on the surface of Li@COF-105 with the $\mathrm{O} 7-\mathrm{Li}$ distance of $1.975 \AA$. The bond angle $\mathrm{C} 1-\mathrm{Si}-\mathrm{C} 7$ is $99.81^{\circ}$ in $\mathrm{SO}_{2} / \mathrm{Li} @ \mathrm{COF}-105$, with the distances of $\mathrm{C} 1-\mathrm{Li}$ and C7-Li being $2.353 \AA$ and $2.363 \AA$, respectively. AIM calculations further show that there is a bond critical point $\mathrm{BCP}_{\mathrm{O} 7-\mathrm{Li}}$ within the adsorption complex $\mathrm{SO}_{2} / \mathrm{Li} @ \mathrm{COF}-$ 105, with charge density being 0.0268 a.u. Further, NBO results presented in Table 5 indicate that the absorbed $\mathrm{SO}_{2}$ molecule could interact with Li@COF-105 by the dominant donor-acceptor delocalization between 1-center lone pair of atom $\mathrm{O} 7$ and 1-center non-Lewis lone pair of atom Li. These results indicate that the modifications of doping $\mathrm{Li}$ into COF-105 enhance the affinity of the host material to the sulfur dioxide gas molecule significantly, compared to the nondoped ones in which $\mathrm{SO}_{2} / \mathrm{COF}-105$ interaction energy is $-2.57 \mathrm{kcal} / \mathrm{mol}$ derived from DFT calculations at B3LYP/6-311 + G(d,p)//B3LYP/6-31G(d) level of theory. In addition, there are weak interactions between the absorbed $\mathrm{SO}_{2}$ molecule and the TBPS building block of COF-105, with the charge density of $\mathrm{BCP}_{\mathrm{O} 7-\mathrm{C} 4}$ and $\mathrm{BCP}_{\mathrm{O} 8-\mathrm{C} 10}$ being 0.0028 a.u. and 0.0055 a.u., respectively.

Similarly, the Na-doped COF-105 and K-doped COF105 complexes also can absorb one $\mathrm{SO}_{2}$ molecule with the interaction energy of -21.87 and $-19.14 \mathrm{kcal} / \mathrm{mol}$, where $\mathrm{SO}_{2}$ lies on the surface with the $\mathrm{O} 7-\mathrm{Na}$ and $\mathrm{O} 7-\mathrm{K}$ distance of $2.279 \AA$ and $2.718 \AA$, respectively. Charge densities of $\mathrm{BCP}_{\mathrm{O} 7-\mathrm{Na}}$ and $\mathrm{BCP}_{\mathrm{O} 7-\mathrm{K}}$ in the adsorption complexes $\mathrm{SO}_{2} / \mathrm{Na} @ \mathrm{COF}-105$ and $\mathrm{SO}_{2} / \mathrm{K} @ \mathrm{COF}-105$ are 0.0205 a.u. and 0.0158 a.u., respectively, and are weaker than those of the adsorption complex $\mathrm{SO}_{2} / \mathrm{Li} \mathrm{COF}-105$.

On the contrary, the interaction energy between the absorbed $\mathrm{SO}_{2}$ molecule and the Sc-doped covalent organic frameworks is $-41.36 \mathrm{kcal} / \mathrm{mol}$, obtained by subtracting the energies of sulfur dioxide and the metal-doped covalent organic frameworks from the energy of the adsorption complexes $\mathrm{SO}_{2} / \mathrm{Sc} @ \mathrm{COF}-105$. The $\mathrm{SO}_{2}$ gas molecule nearly lies onto the surface of Sc@COF-105 with the O7-Sc distance of $1.963 \AA$. There is a $(3,-1)$ bond critical point $\mathrm{BCP}_{\mathrm{O} 7-\mathrm{Sc}}$ between $\mathrm{O} 7$ atom of the absorbed $\mathrm{SO}_{2}$ molecule and Sc@ COF-105 within the adsorption complex SO $2 / \mathrm{Sc} @ \mathrm{COF}-105$, with charge density and energy density being 0.1226 a.u. and -0.0750 a.u, respectively. Further, NBO results presented in Table 5 also indicate that the absorbed $\mathrm{SO}_{2}$ molecule could interact with Sc@COF-105 by the dominant donor-acceptor delocalization between 1-center lone pair of atom $\mathrm{O} 7$ and 1-center non-Lewis lone pair of atom Sc.

\section{Conclusions}

In this work, density functional theory calculations have been performed to investigate the properties of metal-doped covalent organic frameworks and their interactions with $\mathrm{SO}_{2}$ gas. We have doped alkali ( $\mathrm{Li}, \mathrm{Na}$, and $\mathrm{K}$ ) and transition 


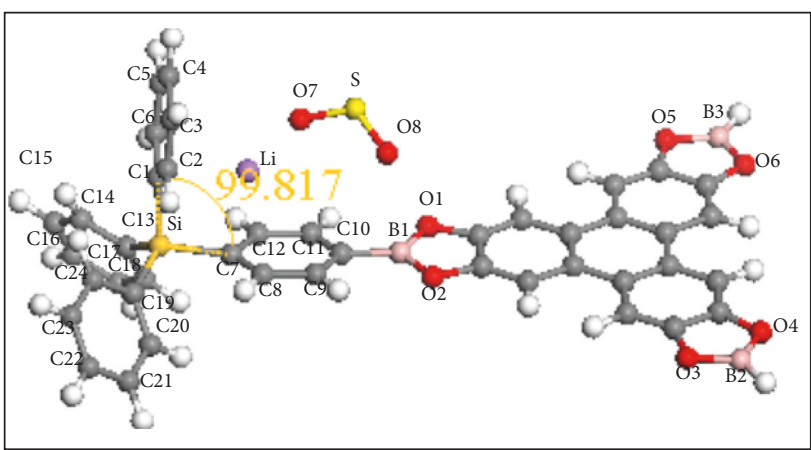

(a)

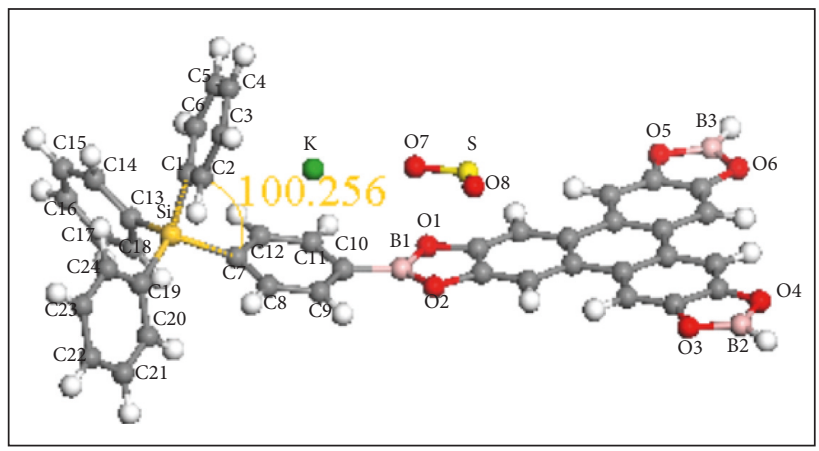

(c)

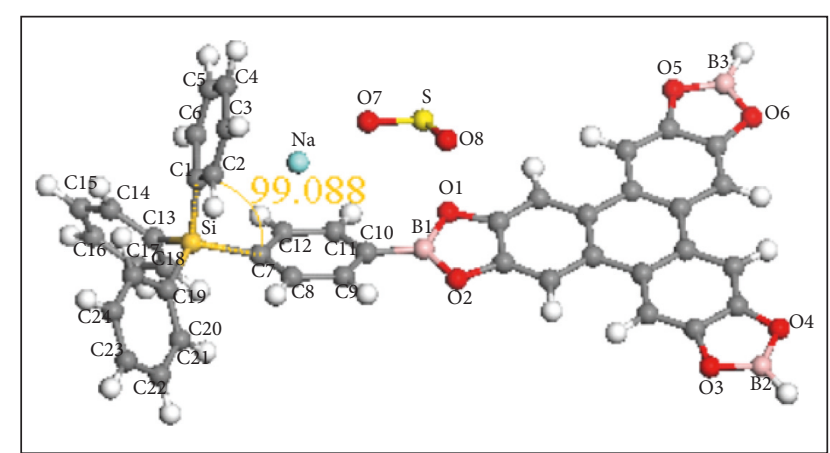

(b)

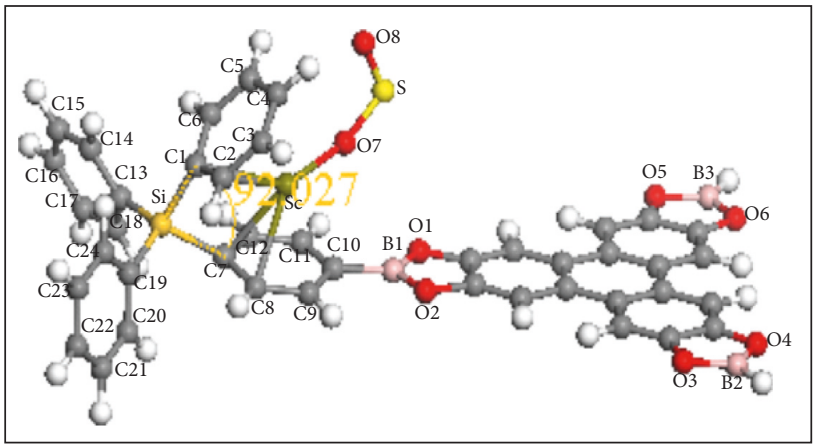

(d)

FIGURE 4: Optimized geometries of all the adsorption complexes $\mathrm{SO}_{2} /$ metal@COF-105. Dark yellow: Si; black: C; grey: $\mathrm{H}$; pink: B; red: O; purple: Li; blue: Na; green: K; khaki: Sc; yellow: S. Partial atom numbers of C, B, and O atoms were presented. (a) SO $2 / \mathrm{Li} @ \mathrm{COF}-105$. (b) $\mathrm{SO}_{2} / \mathrm{Na} @ \mathrm{COF}-105$. (c) $\mathrm{SO}_{2} / \mathrm{K} @ \mathrm{COF}-105$. (d) $\mathrm{SO}_{2} / \mathrm{Sc} @ \mathrm{COF}-105$.

TABle 3: Partial geometrical data of the adsorption complexes $\mathrm{SO}_{2} /$ metal@COF-105.

\begin{tabular}{|c|c|c|c|c|}
\hline Angle $\left({ }^{\circ}\right)$ /atom distances $(\AA)$ & $\mathrm{SO}_{2} / \mathrm{Li} @ \mathrm{COF}-105$ & $\mathrm{SO}_{2} / \mathrm{Na} @ \mathrm{COF}-105$ & $\mathrm{SO}_{2} / \mathrm{K} @ \mathrm{COF}-105$ & $\mathrm{SO}_{2} / \mathrm{Sc} @ \mathrm{COF}-105$ \\
\hline $\mathrm{C} 1-\mathrm{Si}-\mathrm{C} 7$ & 99.81 & 99.08 & 100.25 & 92.02 \\
\hline $\mathrm{O} 7-\mathrm{S}-\mathrm{O} 8$ & 116.45 & 116.23 & 115.85 & 110.08 \\
\hline O7-metal & 1.975 & 2.279 & 2.718 & 1.963 \\
\hline O8-metal & 3.742 & 4.062 & 4.537 & 3.916 \\
\hline S-metal & 3.261 & 3.663 & 4.095 & 3.451 \\
\hline C1-metal & 2.353 & 2.754 & 4.190 & 2.489 \\
\hline C2-metal & 2.706 & 2.879 & 3.316 & 2.593 \\
\hline C3-metal & 3.231 & 3.087 & 3.396 & 2.719 \\
\hline C4-metal & 3.421 & 3.162 & 3.434 & 2.738 \\
\hline C5-metal & 3.130 & 3.044 & 3.397 & 2.680 \\
\hline C6-metal & 2.587 & 2.833 & 3.318 & 2.547 \\
\hline C7-metal & 2.363 & 2.841 & 3.326 & 2.484 \\
\hline C8-metal & 2.716 & 3.091 & 3.307 & 2.550 \\
\hline C9-metal & 3.215 & 3.304 & 3.293 & 2.624 \\
\hline C10-metal & 3.396 & 3.272 & 3.295 & 2.640 \\
\hline C11-metal & 3.087 & 3.033 & 3.347 & 2.639 \\
\hline C12-metal & 2.570 & 2.820 & 3.358 & 2.569 \\
\hline
\end{tabular}

metals (Sc) doped into the COF-105 cluster model and investigated properties of the metal-doped covalent organic frameworks and their interactions with the $\mathrm{SO}_{2}$ gas molecule. It is found that that a single metal atom (including Li, $\mathrm{Na}, \mathrm{K}$, and Sc) doped at the top of phenyls in the TBPS building block can easily lose its valence electrons and can be positively charged and stably attached to the frameworks of the COF-105 cluster model. The metal-doped COF-105 complexes Li@COF-105, Na@COF-105, K@COF-105, and Sc@COF-105 could exist stably.

In the adsorption complexes $\mathrm{SO}_{2} / \mathrm{Li} @ \mathrm{COF}-105$, $\mathrm{SO}_{2} / \mathrm{Na} @ \mathrm{COF}-105$, and $\mathrm{SO}_{2} / \mathrm{K} @ \mathrm{COF}-105$, the calculated interaction energy between the absorbed $\mathrm{SO}_{2}$ gas molecule and the metal-doped COF-105 complexes is $-25.46,-21.87$, and $-19.14 \mathrm{kcal} / \mathrm{mol}$, respectively. The $\mathrm{SO}_{2}$ gas molecule nearly lies on the surface of the alkali metal-doped COF-105 cluster 
TABle 4: Properties of partial interactions within the adsorption complexes $\mathrm{SO}_{2} /$ metal@COF-105.

\begin{tabular}{|c|c|c|c|c|c|c|c|}
\hline BCP & & $\rho$ & $\nabla^{2} \rho$ & $E$ & G & $V$ & $\left|V_{\mathrm{BCP}}\right| / G_{\mathrm{BCP}}$ \\
\hline \multirow{5}{*}{$\mathrm{SO}_{2} / \mathrm{Li} @ \mathrm{COF}-105$} & $\mathrm{O} 7-\mathrm{C} 4$ & 0.0028 & 0.0094 & 0.0004 & 0.0019 & -0.0015 & 0.7747 \\
\hline & O7-Li & 0.0268 & 0.2060 & 0.0113 & 0.0402 & -0.0290 & 0.7198 \\
\hline & $\mathrm{O} 8-\mathrm{C} 10$ & 0.0055 & 0.0187 & 0.0008 & 0.0038 & -0.0030 & 0.7796 \\
\hline & $\mathrm{Li}-\mathrm{C} 1$ & 0.0143 & 0.0644 & 0.0025 & 0.0136 & -0.0110 & 0.8130 \\
\hline & $\mathrm{Li}-\mathrm{C} 7$ & 0.0139 & 0.0637 & 0.0026 & 0.0134 & -0.0108 & 0.8083 \\
\hline \multirow{5}{*}{$\mathrm{SO}_{2} / \mathrm{Na} @ \mathrm{COF}-105$} & S-O1 & 0.0140 & 0.0424 & 0.0009 & 0.0097 & -0.0088 & 0.9093 \\
\hline & $\mathrm{O} 7-\mathrm{C} 11$ & 0.0052 & 0.0148 & 0.0005 & 0.0032 & -0.0027 & 0.8374 \\
\hline & $\mathrm{O} 7-\mathrm{Na}$ & 0.0205 & 0.1348 & 0.0063 & 0.0274 & -0.0210 & 0.7686 \\
\hline & $\mathrm{Na}-\mathrm{C} 1$ & 0.0106 & 0.0472 & 0.0018 & 0.0100 & -0.0082 & 0.8182 \\
\hline & $\mathrm{Na}-\mathrm{C} 12$ & 0.0095 & 0.0411 & 0.0016 & 0.0086 & -0.0070 & 0.8122 \\
\hline \multirow{4}{*}{$\mathrm{SO}_{2} / \mathrm{K} @ \mathrm{COF}-105$} & $\mathrm{O} 7-\mathrm{O} 2$ & 0.0062 & 0.0228 & 0.0009 & 0.0048 & -0.0039 & 0.8087 \\
\hline & $\mathrm{O} 7-\mathrm{K}$ & 0.0157 & 0.0713 & 0.0023 & 0.0156 & -0.0133 & 0.8552 \\
\hline & $\mathrm{K}-\mathrm{C} 9$ & 0.0069 & 0.0267 & 0.0013 & 0.0054 & -0.0041 & 0.7635 \\
\hline & $\mathrm{K}-\mathrm{C} 1$ & 0.0070 & 0.0267 & 0.0012 & 0.0054 & -0.0042 & 0.7711 \\
\hline \multirow{5}{*}{$\mathrm{SO}_{2 /} \mathrm{Sc} @ \mathrm{COF}-105$} & $\mathrm{O} 8-\mathrm{C} 5$ & 0.0081 & 0.0327 & 0.0014 & 0.0067 & -0.0053 & 0.7877 \\
\hline & $\mathrm{O} 7-\mathrm{Sc}$ & 0.1226 & 0.2582 & -0.0750 & 0.1395 & -0.2145 & 1.5374 \\
\hline & Sc-C11 & 0.0251 & 0.0935 & 0.0029 & 0.0204 & -0.0175 & 0.8563 \\
\hline & $\mathrm{Sc}-\mathrm{C} 7$ & 0.0377 & 0.1146 & 0.0002 & 0.0285 & -0.0283 & 0.9937 \\
\hline & Sc-C1 & 0.0371 & 0.1146 & 0.0003 & 0.0284 & -0.0281 & 0.9900 \\
\hline
\end{tabular}

TABLE 5: NBO analysis at B3LYP/6-31G(d) level of theory for the adsorption complexes $\mathrm{SO}_{2} /$ metal@COF-105 (selected values) ${ }^{1}$.

\begin{tabular}{|c|c|c|c|c|c|c|}
\hline Complex & Donor NBOs & Acceptor NBOs & $E^{(2)}(\mathrm{kcal} / \mathrm{mol})$ & $E(j)-E(i)$ (a.u.) & $F(i, j)$ (a.u.) & Principle delocalization types \\
\hline \multirow{6}{*}{$\mathrm{SO}_{2} / \mathrm{Li} @ \mathrm{COF}-105$} & $\mathrm{BD} *(2) \mathrm{S}-\mathrm{O} 8$ & $\mathrm{LP} *(2) \mathrm{B} 1$ & 2.87 & 0.01 & 0.009 & Remote \\
\hline & $\mathrm{BD}(1) \mathrm{S}-\mathrm{O} 8$ & $\mathrm{LP} *(1) \mathrm{Li}$ & 1.73 & 0.78 & 0.034 & Remote \\
\hline & $\mathrm{BD}(1) \mathrm{S}-\mathrm{O} 7$ & $\mathrm{LP} *(1) \mathrm{Li}$ & 6.85 & 1.00 & 0.076 & Remote \\
\hline & CR (2) S & $\mathrm{LP} *(1) \mathrm{Li}$ & 7.53 & 9.15 & 0.242 & Remote \\
\hline & LP (1) S & $\mathrm{LP} *(1) \mathrm{Li}$ & 18.79 & 0.76 & 0.109 & Remote \\
\hline & LP (1) O7 & $\mathrm{LP} *(1) \mathrm{Li}$ & 26.25 & 0.91 & 0.141 & Remote \\
\hline \multirow{6}{*}{$\mathrm{SO}_{2} / \mathrm{Na} @ \mathrm{COF}-105$} & $\mathrm{BD}(1) \mathrm{S}-\mathrm{O} 8$ & $\mathrm{LP} *(1) \mathrm{Na}$ & 1.05 & 1.02 & 0.030 & Remote \\
\hline & $\mathrm{BD}(1) \mathrm{S}-\mathrm{O} 7$ & $\mathrm{LP} *(1) \mathrm{Na}$ & 3.75 & 1.00 & 0.056 & Remote \\
\hline & CR (2) S & $\mathrm{LP} *(1) \mathrm{Na}$ & 3.68 & 9.20 & 0.168 & Remote \\
\hline & CR (1) O7 & $\mathrm{LP} *(1) \mathrm{Na}$ & 2.73 & 19.11 & 0.208 & Remote \\
\hline & LP (1) S & $\mathrm{LP} *(1) \mathrm{Na}$ & 9.35 & 0.75 & 0.076 & Remote \\
\hline & LP (1) O7 & $\mathrm{LP} *(1) \mathrm{Na}$ & 19.47 & 0.90 & 0.120 & Remote \\
\hline \multirow{5}{*}{$\mathrm{SO}_{2} / \mathrm{K} @ \mathrm{COF}-105$} & $\mathrm{BD}(1) \mathrm{S}-\mathrm{O} 7$ & $\mathrm{LP} *(1) \mathrm{K}$ & 1.60 & 0.99 & 0.036 & Remote \\
\hline & CR (2) S & $L P *(1) K$ & 1.66 & 9.33 & 0.113 & Remote \\
\hline & CR (1) O7 & $\mathrm{LP} *(1) \mathrm{K}$ & 1.95 & 19.10 & 0.175 & Remote \\
\hline & LP (1) S & $\mathrm{LP} *(1) \mathrm{K}$ & 4.24 & 0.74 & 0.051 & Remote \\
\hline & LP (1) O7 & $\mathrm{LP} *(1) \mathrm{K}$ & 14.56 & 0.90 & 0.103 & Remote \\
\hline \multirow{7}{*}{$\mathrm{SO}_{2} / \mathrm{Sc} @ \mathrm{COF}-105$} & $\mathrm{BD} *(1) \mathrm{S}-\mathrm{Sc}$ & $\mathrm{RY} *(1) \mathrm{O} 8$ & 0.76 & 1.36 & 0.032 & Vicinal \\
\hline & $\mathrm{BD} *(1) \mathrm{S}-\mathrm{Sc}$ & $\mathrm{BD}(1) \mathrm{S}-\mathrm{Sc}$ & 6.74 & 0.14 & 0.064 & Geminal \\
\hline & $\mathrm{CR}(3) \mathrm{Sc}$ & $\mathrm{BD} *(1) \mathrm{S}-\mathrm{O} 7$ & 2.70 & 2.77 & 0.080 & Vicinal \\
\hline & $\mathrm{LP}(2) \mathrm{O} 7$ & $\mathrm{LP} *(1) \mathrm{Sc}$ & 84.93 & 0.73 & 0.225 & Remote \\
\hline & $\mathrm{LP}(2) \mathrm{O} 8$ & $\mathrm{RY} *(1) \mathrm{Sc}$ & 0.97 & 1.35 & 0.034 & Remote \\
\hline & $\mathrm{LP} *(2) \mathrm{Sc}$ & $\mathrm{BD} *(1) \mathrm{S}-\mathrm{O} 7$ & 1.70 & 0.18 & 0.038 & Vicinal \\
\hline & $\mathrm{BD}(1) \mathrm{S}-\mathrm{Sc}$ & $\mathrm{LP} *(8) \mathrm{Sc}$ & 0.66 & 0.06 & 0.013 & Geminal \\
\hline
\end{tabular}

${ }^{1} \mathrm{BD}$ denotes the formally occupied 2-center bonding orbital. RY* denotes 1-center Rydberg. LP denotes 1-center lone pair. The unstarred and starred labels denote Lewis and non-Lewis NBOs, respectively.

model with the O7-Li, O7- Na, and O7-K atom distance of $1.975 \AA, 2.273 \AA$, and $2.719 \AA$, respectively. The absorbed $\mathrm{SO}_{2}$ molecule could interact with alkali metal@COF-105 by the dominant donor-acceptor delocalization between 1-center lone pair of atom $\mathrm{O} 7$ and 1-center non-Lewis lone pair of alkali metal atom. Further, AIM calculations indicate charge densities of $\mathrm{BCP}_{\mathrm{O} 7-\mathrm{Li}}, \mathrm{BCP}_{\mathrm{O} 7-\mathrm{Na}}$, and $\mathrm{BCP}_{\mathrm{O} 7-\mathrm{K}}$ being 0.0268 a.u., 0.0205 a.u., and 0.0158 a.u., respectively.
In the adsorption complex $\mathrm{SO}_{2} / \mathrm{Sc} @ \mathrm{COF}-105$, the total interaction energy between the absorbed $\mathrm{SO}_{2}$ molecule and the Sc-doped COF-105 complex is $-41.36 \mathrm{kcal} / \mathrm{mol}$, much larger than those of the adsorption complexes $\mathrm{SO}_{2} / \mathrm{Li} @ \mathrm{COF}$ 105, SO 2 / Na@COF-105, and $\mathrm{SO}_{2} / \mathrm{K} @ \mathrm{COF}-105$. The $\mathrm{SO}_{2}$ gas molecule nearly lies onto the surface of Sc@COF-105 with the O7-Sc distance of $1.963 \AA$. NBO calculations indicate that the absorbed $\mathrm{SO}_{2}$ molecule could interact with Sc@COF-105 by 
the dominant donor-acceptor delocalization between 1-center lone pair of atom $\mathrm{O} 7$ and 1-center non-Lewis lone pair of atom Sc. AIM calculations also indicate there is a $(3,-1)$ bond critical point $\mathrm{BCP}_{\mathrm{O} 7-\mathrm{Sc}}$ between $\mathrm{O} 7$ atom of the absorbed $\mathrm{SO}_{2}$ molecule and Sc@COF-105 within the adsorption complex $\mathrm{SO}_{2} / \mathrm{Sc} @ \mathrm{COF}-105$, with charge density and energy density being 0.1226 a.u. and -0.0750 a.u, respectively.

\section{Data Availability}

The data used to support the findings of this study are available from the corresponding author upon request.

\section{Conflicts of Interest}

The authors declare no conflicts of interest.

\section{Acknowledgments}

This work was supported by the NSFC of China (Grant no. 21507099) and the Scientific Research Fund of Xuzhou University of Technology (XKY2016113).

\section{Supplementary Materials}

Supplementary file presents the NBO analysis results at B3LYP/6-31G(d) level of theory for the adsorption complexes SO $2 / \mathrm{Li} @ \mathrm{COF}-105, \mathrm{SO}_{2} / \mathrm{Na} @ \mathrm{COF}-105, \mathrm{SO}_{2} / \mathrm{K} @ \mathrm{COF}-$ 105, and $\mathrm{SO}_{2} / \mathrm{Sc} @ \mathrm{COF}-105$, respectively. (Supplementary Materials)

\section{References}

[1] S. M. Nazrul Islam, P. L. Jackson, and J. Aherne, “Ambient nitrogen dioxide and sulfur dioxide concentrations over a region of natural gas production, Northeastern British Columbia, Canada," Atmospheric Environment, vol. 143, pp. 139-151, 2016.

[2] J. Ma and J. Xu, "Environment: China's energy rush harming ecosystem," Nature, vol. 541, no. 7635, p. 30, 2017.

[3] F. Zaza, C. Paoletti, and R. LoPresti, "Studies on sulfur poisoning and development of advanced anodic materials for waste-to-energy fuel cells applications," Journal of Power Sources, vol. 195, no. 13, pp. 4043-4050, 2010.

[4] Z. G. Hu, X. D. Tan, and F. Yang, "Integrated resource strategic planning: case study of energy efficiency in the Chinese power sector," Energy Policy, vol. 38, no. 11, pp. 6391-6397, 2010.

[5] M. F. Aguiar and G. L. Goelho, "Adsorption of sulfur compounds from natural gas by different adsorbents and desorption using supercritical $\mathrm{CO}_{2}$," Journal of Environmental Chemical Engineering, vol. 5, no. 5, pp. 4353-4364, 2017.

[6] M. D. Frogley, C. C. Tang, and C. Murray, "Selective adsorption of sulfur dioxide in a robust metal organic framework material," Advanced Materials, vol. 28, no. 39, pp. 8705-8711, 2016.

[7] Y. Mathieu, L. Tzanis, and M. Soulard, "Adsorption of $\mathrm{SO}_{\mathrm{x}}$ by oxide materials: a review," Fuel Processing Technology, vol. 114, pp. 81-100, 2013.

[8] X. Cui, Q. Yang, and L. Yang, "Ultrahigh and selective $\mathrm{SO}_{2}$ uptake in inorganic anion-pillared hybrid porous materials," Advanced Materials, vol. 29, no. 28, article 1606929, 2017.
[9] L. B. Wu, D. An, and J. Dong, "Preparation and $\mathrm{SO}_{2}$ absorption/desorption properties of crosslinked poly(1,1,3,3tetramethylguanidine acrylate) porous particles," Macromolecular Rapid Communications, vol. 27, no. 22, pp. 1949-1954, 2006.

[10] K. Tan, S. Zuluaga, and Q. H. Gong, "Competitive coadsorption of $\mathrm{CO}_{2}$ with $\mathrm{H}_{2} \mathrm{O}, \mathrm{NH}_{3}, \mathrm{SO}_{2}, \mathrm{NO}, \mathrm{NO}_{2}, \mathrm{~N}_{2}, \mathrm{O}_{2}$, and $\mathrm{CH}_{4}$ in M-MOF-74 (M= Mg, $\left.\mathrm{Co}, \mathrm{Ni}\right)$ : the role of hydrogen bonding," Chemistry of Materials, vol. 27, no. 6, pp. 2203-2217, 2015.

[11] M. M. Tong, Y. S. Lan, and Q. Y. Yang, "Exploring the structure-property relationships of covalent organic frameworks for noble gas separations," Chemical Engineering Science, vol. 168, pp. 456-464, 2017.

[12] M. X. Wu and Y. W. Yang, "Applications of covalent organic frameworks (COFs): from gas storage and separation to drug delivery," Chinese Chemical Letters, vol. 28, no. 6, pp. 11351143, 2017.

[13] Y. F. Zeng, R. Q. Zou, and Y. L. Zhao, "Covalent organic frameworks for $\mathrm{CO}_{2}$ capture," Advanced Materials, vol. 28, no. 15, pp. 2855-2873, 2016.

[14] Y. Du, H. S. Yang, and J. M. Whiteley, "Ionic covalent organic frameworks with spiroborate linkage," Angewandte Chemie International Edition, vol. 55, no. 5, pp. 1737-1741, 2016.

[15] C. S. Diercks and O. M. Yaghi, "The atom, the molecule, and the covalent organic framework," Science, vol. 355, no. 6328, pp. 9231-9238, 2017.

[16] G. Y. Lee, J. Lee, and S. Kim, “Amine-functionalized covalent organic frameworks for efficient $\mathrm{SO}_{2}$ capture with high reversibility," Scientific Reports, vol. 7, no. 1, 2017.

[17] J. H. Lan, D. Cao, and W. C. Wang, "Li-doped and nondoped covalent organic borosilicate framework for hydrogen storage," Journal of Physical Chemistry C, vol. 114, no. 7, pp. 3108-3114, 2010.

[18] Z. L. Yang and D. P. Cao, "Effect of Li doping on diffusion and separation of hydrogen and methane in covalent organic frameworks," Journal of Physical Chemistry C, vol. 116, no. 23, pp. 12591-12598, 2012.

[19] C. Y. Bai, J. Li, and S. Liu, "In situ preparation of nitrogen-rich and functional ultramicroporous carbonaceous COFs by "segregated" microwave irradiation," Microporous and Mesoporous Materials, vol. 197, pp. 148-155, 2014.

[20] M. M. Wu, Q. Wang, and Q. Sun, "First-principles study of hydrogen adsorption in metal-doped COF-10," Journal of Chemical Physics, vol. 133, no. 15, article 154706, 2010.

[21] R. T. Yang, Y. W. Li, and A. J. Lachawiec, "Chemical bridges for enhancing hydrogen storage by spillover and methods forming the same," US Patent 11/42.898, 2007.

[22] J. H. Guo, X. L. Cheng, and S. J. Li, "Theoretical study of a bridging-spillover mechanism in covalent organic frameworks on $\mathrm{Pt}_{4}$ and $\mathrm{Pt}_{6}$ cluster models," Journal of Physical Chemistry C, vol. 120, no. 31, pp. 17153-17164, 2016.

[23] L. Stegbauer, M. W. Hahn, and A. Jentys, "Tunable water and $\mathrm{CO}_{2}$ sorption properties in isostructural azine-based covalent organic frameworks through polarity engineering," Chemistry of Materials, vol. 27, no. 23, pp. 7874-7881, 2015.

[24] H. M. El-Kaderi, J. R. Hunt, and O. M. Yaghi, "Designed synthesis of 3D covalent organic frameworks," Science, vol. 316, no. 5822, pp. 268-272, 2007.

[25] A. D. Becke, "Density-functional exchange-energy approximation with correct asymptotic-behavior," Physical Review A, vol. 38, no. 6, pp. 3098-3100, 1988. 
[26] F. B. van Duijneveldt, J. G. van Duijneveldt-van de Rijdt, and J. H. van Lenthe, "State-of the-art in counterpoise theory," Chemical Reviews, vol. 94, no. 7, pp. 1873-1885, 1994.

[27] M. J. Frisch, G. W. Trucks, and H. B. Schlegel, Gaussian 09, Revision A.02, Gaussian, Inc., Wallingford, CT, USA, 2009.

[28] F. Biegler-König, J. Schönbohm, and R. Derdau, AIM2000, McMaster University, Hamilton, ON, Canada, 2002. 

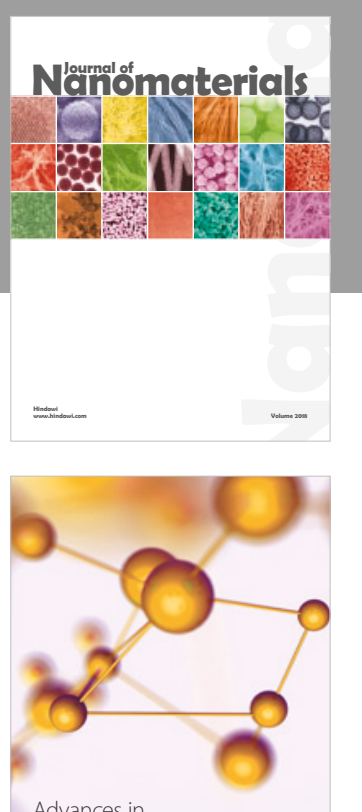

Physical Chemistry
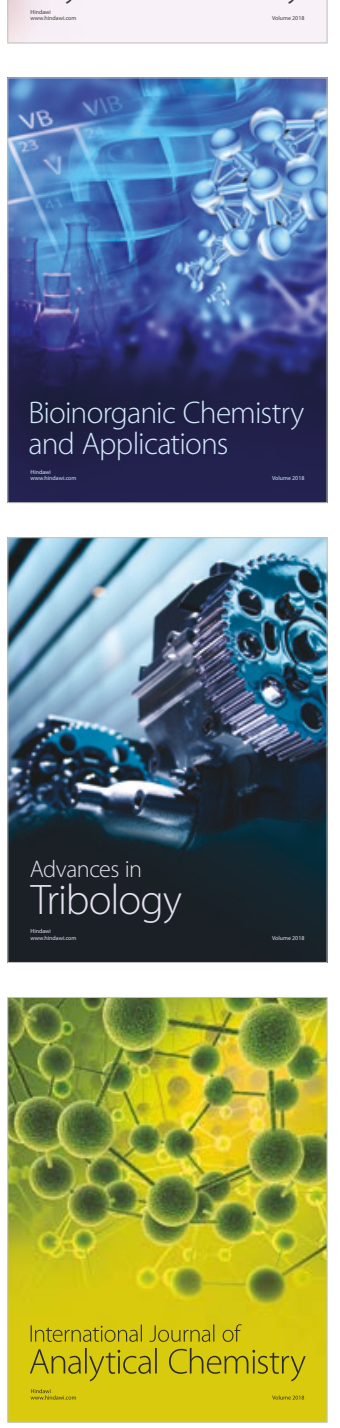

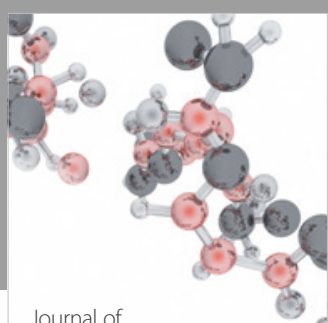

Analytical Methods

in Chemistry

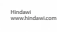

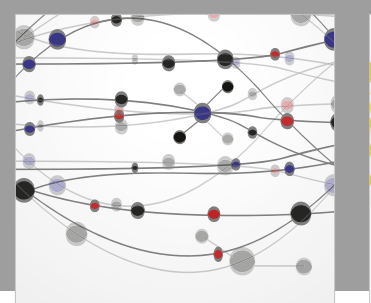

The Scientific World Journal

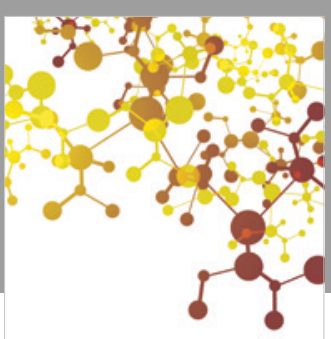

Journal of

Applied Chemistry
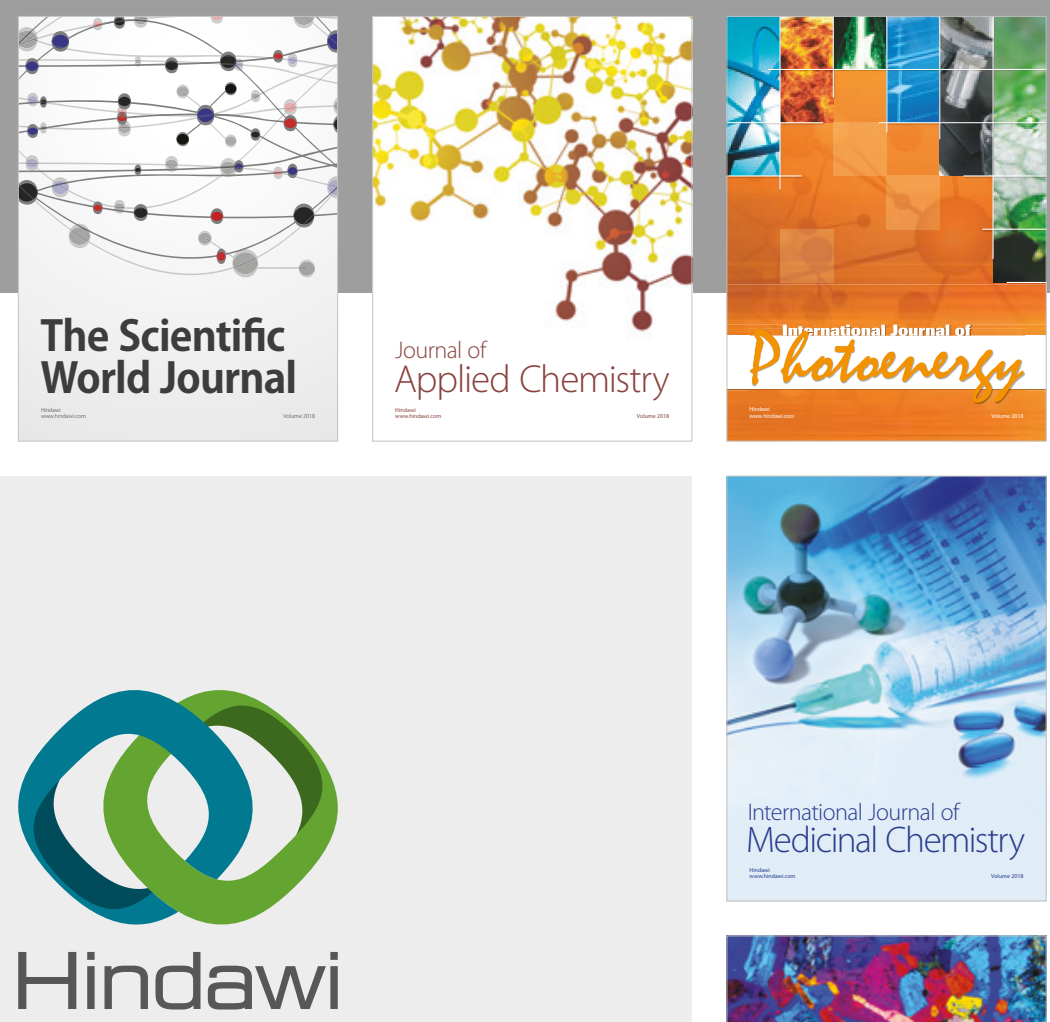

Submit your manuscripts at

www.hindawi.com
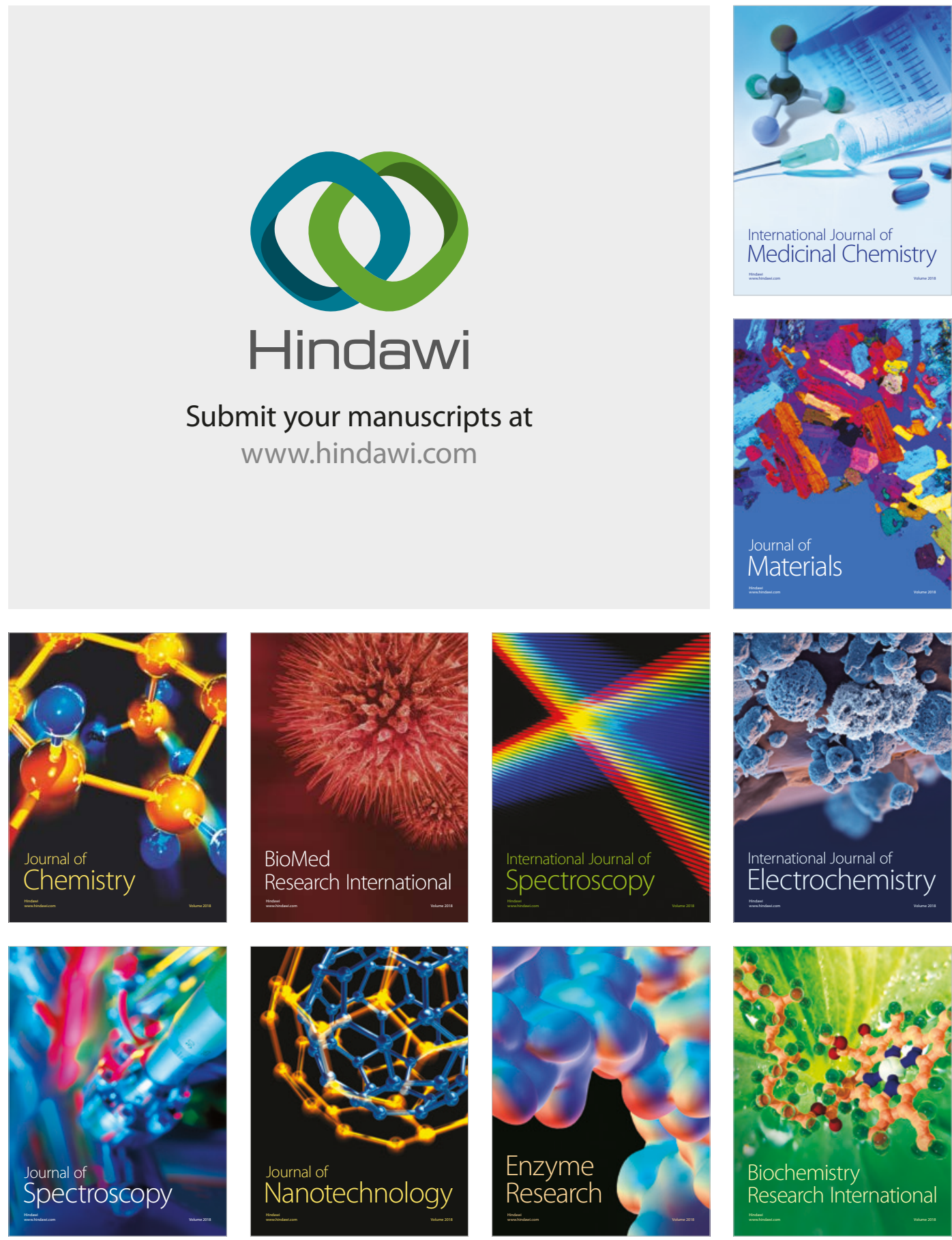
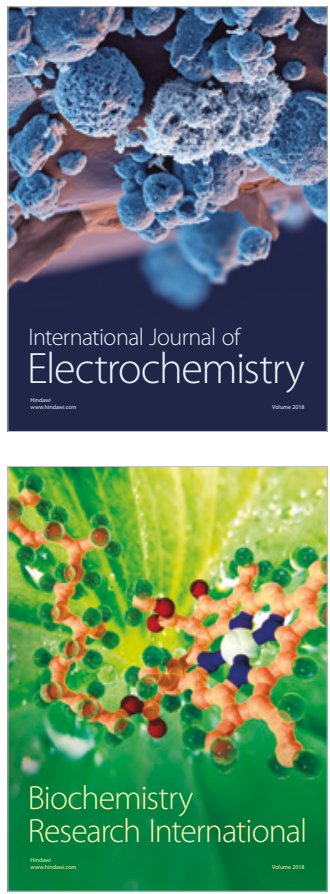